\title{
PROGRAM PENGABDIAN KEPADA MASYARAKAT: PENDIDIKAN ANTI KORUPSI KEPADA ANAK USIA SEKOLAH SEBAGAI UPAYA PENCAPAIAN SUSTAINABLE DEVELOPMENT GOALS (SDGS) TUJUAN 16 TARGET 5
}

\author{
Denik Iswardani Witarti ${ }^{\circledR 1}$, Anggun Puspitasari ${ }^{\circledR 2)}$, dan Arin Fithriana ${ }^{(3)}$ \\ ${ }^{1}$ Ilmu Komunikasi, Fakultas Ilmu Komunikasi, Universitas Budi Luhur \\ ${ }^{2,3}$ Ilmu Hubungan Internasional, Fakultas Ilmu Sosial dan Ilmu Politik, Universitas Budi Luhur \\ ${ }^{1,2,3}$ Jl. Ciledug Raya, Petukangan Utara, Kec. Pesanggrahan, Kota Jakarta Selatan, \\ Daerah Khusus Ibukota Jakarta, 12260 \\ E-mail : denik.iswardani@budiluhur.ac.id ${ }^{1)}$, anggun.puspitasari@budiluhur.ac.id ${ }^{2)}$, arin.fithriana@budiluhur.ac.id ${ }^{3)}$
}

\begin{abstract}
ABSTRAK
Sustainable Development Goals (SDGs) tujuan 16 berusaha untuk mencapai kehidupan masyarakat yang damai dan inklusif untuk pembangunan berkelanjutan, menyediakan akses terhadap keadilan bagi semua dan membangun institusi yang efektif, akun tabel dan inklusif di semua tingkatan. Dalam upaya mencapai tujuan tersebut, telah disusun beberapa target. PKM ini dilakukan sebagai untuk mencapai sasaran ke 5 yaitu secara substansial mengurangi korupsi dan suap dalam segala bentuknya. Isu korupsi dan suap di Indonesia telah menjadi permasalahan yang serius. RPJMN secara eksplisit mengakui bahwa korupsi merupakan hambatan utama untuk mencapai pembangunan berkelanjutan. Tindakan korupsi dan suap bisa dicegah dengan memberikan pendidikan sejak dini. Kegiatan di Sekolah Madrasah Tsanawiyah (MTs) Al Musyarrofah dilakukan untuk mengenalkan pentingnya gerakan anti korupsi dan suap dalam segala bentuknya kepada masyarakat khususnya anak-anak usia sekolah. Kegiatan yang dilakukan melalui bentuk seminar dan diskusi kelompok ini diikuti oleh 43 siswa pengurus OSIS MTs Al Musyarrofah. Setelah mengikuti kegiatan ini, peserta menyampaikan bahwa sikap jujur, penguatan Komite Pemberantasan Korupsi (KPK) serta ketegasan penegakan hukum dapat mencegah dan meminimalisir tindak suap dan korupsi.
\end{abstract}

Kata Kunci: SDGs, Korupsi, Sekolah, Anak, Tujuan 16

\section{PENDAHULUAN}

Setelah menjalankan program Millenium Development Goals (MDGs), United Nations (UN) atau Persatuan Bangsa-Bangsa (PBB) kini mencanangkan Sustainable Development Goals (SDGs) sebagai program lanjutannya. SDGs atau yang dikenal juga sebagai "Global Goals" merupakan suatu ajakan bersama (universal) untuk melakukan aksi dengan tujuan mengakhiri kemiskinan, melindungi bumi dan menjamin bahwa semua orang dapat menikmati hidup yang damai dan sejahtera. SDGs menambahkan area baru dalam prioritas yang akan dicapai seperti perubahan iklim, kesetaraan ekonomi, konsumsi yang berkelanjutan, keadilan dan perdamaian. (www.UNDP.org diakses 19 Maret 2021).

Pada 25 September 2015, 193 anggota Majelis Umum PBB mengadopsi Agenda Pembangunan tahun 2030 yang berjudul " Transforming our world: the 2030 Development Agenda for Sustainable Development" yang kemudian disebut sebagai SDGs. 17 goals dan 169 target SDGs termuat dalam Resolusi PBB A/RES/70/1 paragraf 54. (Fukuda-Parr, 2016).

Sebagai konsekuensi dari diadopsinya Resolusi tersebut, seluruh badan (agencies) di bawah PBB, negara anggota serta masyarakat global harus mendukung goals yang hendak dicapai, termasuk Indonesia. (Thamrin, 2020) Pelaksanaan SGDs ini dilandasi oleh semangat kemitraan yang melibatkan semua entitas termasuk civitas akademik. Sebagai wujud sumbangan nyata, civitas akademik terutama dosen dan mahasiswa dapat memasukkan agenda SDGs sebagai bahan kajian maupun dalam kegiatan Pengabdian Kepada Masyarakat (PKM). Tujuan dan target dalam SDGs juga sesuai dengan filosofi Universitas Budi Luhur yang berusaha menghasilkan insan cerdas dan berbudi luhur.

Fokus PKM ini adalah tujuan no 16 yaitu mempromosikan masyarakat yang damai dan inklusif untuk pembangunan berkelanjutan, menyediakan akses terhadap keadilan bagi semua dan membangun institusi yang efektif, akun tabel dan inklusif di semua tingkatan. Tujuan no 16 diuraikan secara rinci dalam beberapa target. PKM ini dilakukan untuk berusaha mencapai sasaran ke 5 yaitu secara substansial mengurangi korupsi dan suap dalam segala bentuknya. (Hope, 2020).

Mengacu kepada definisi yang digunakan oleh World Bank dan United Nations Development Program (UNDP), korupsi diartikan sebagai "the abuse of public office for private gain". Korupsi seringkali melibatkan para pejabat publik yang dengan sengaja menyalah gunakan wewenang yang dimiliki demi keuntungan 
pribadi. Sedangkan menurut UU No. 31 Tahun 1999 Tentang Pemberantasan Tindak Pidana Korupsi, korupsi merupakan tindakan memperkaya diri sendiri, penyalahgunaan wewenang dan kekuasaan, memberi dan menjanjikan sesuatu kepada pejabat atau hakim, berbuat curang, melakukan penggelapan, dan menerima hadiah terkait tanggung jawab yang dijalani. (UNDP Indonesia, 2015).

Menurut laporan UNDP, Indonesia (bersama dengan Albania, Rwanda dan Tunisia) adalah salah satu dari empat negara uji coba SDG 16 tentang tata kelola melalui sebuah inisiatif untuk menelaah kesiapan negara dalam menghasilkan dan memanfaatkan data tata kelola serta menilai komplementaritas tujuan tersebut dengan kebijakan nasional dan daerah. Korupsi adalah salah satu isu utama yang dibahas dalam proyek uji coba SDG 16 dan dalam RPJMN, bab 6.4 yang merangkum arah kebijakan pemerintah tentang tata kelola pemerintahan yang baik. (Bappenas, 2015).

Pada kasus di Indonesia, anti-korupsi telah menjadi agenda nasional sejak diperkenalkannya reformasi politik di tahun 1999 (UU 31/1999 tentang Pemberantasan Tindak Pidana Korupsi). RPJMN secara eksplisit mengakui bahwa korupsi merupakan hambatan utama untuk mencapai pembangunan berkelanjutan (UNDP, 2017:6).

Dalam SDGs 16 dijelaskan bahwa melawan korupsi merupakan kunci yang menentukan keberhasilan tujuan SDGs lainnya, terutama untuk negara-negara yang tingkat korupsinya masih parah, termasuk Indonesia. Transparency International (2017) memperkirakan lebih dari satu dari empat penduduk, atau lebih dari 9 juta penduduk di wilayah Indonesia membayar suap dalam satu tahun terakhir untuk mengakses layanan dasar seperti pendidikan dan kesehatan. (Rulandari, 2020).

Akibatnya kemajuan SDGs 3 untuk kesehatan yang lebih baik dan SDGs 4 untuk pendidikan yang lebih baik menjadi sulit dicapai. Fenomena ini menunjukkan korupsi merupakan ancaman serius bagi 17 tujuan dan 169 target SDGs. Oleh karena itu memerangi korupsi menjadi salah satu prioritas utama dalam SDGs. Secara umum ada 4 target yang terkait dengan agenda antikorupsi di SDGs 16 yaitu target 16.4: memerangi kejahatan terorganisasi dan aliran terlarang; 16.5: melawan korupsi dan penyuapan; 16.6: menciptakan lembaga yang transparan dan bertanggung jawab; dan 16.10: membuka akses ke informasi. Setiap target diformulasikan dalam satu atau dua indikator untuk mengukur kemajuannya. (Biermann, dkk, 2017). Pada kasus Indonesia untuk menjamin keberhasilan SDGs, perhatian utama harus diarahkan kepada target 16.5, yaitu melawan korupsi dan penyuapan. Target ini menyatakan: upaya yang dilakukan harus secara substansial mengurangi korupsi dan penyuapan dalam semua bentuknya. (Badan Pusat Statistik, 2014)

Isu korupsi di Indonesia dapat ditemukan di hampir semua sektor seperti dalam program pelayanan kesehatan, pendidikan, maupun dalam program-program pengentasan kemiskinan. Selain terus mengusahakan pemberantasan, pemerintah juga harus memikirkan bagaimana langkah pencegahan korupsi. Sebagai mitra pemerintah, kampus dapat memberikan sumbangan nyata dengan memberikan pendidikan anti korupsi sejak usia dini. (Abubakar, dkk, 2017).

Pendidikan Anti Korupsi harus ditanamkan sejak usia dini, hal tersebut sejalan dengan program Kemdikbud yang memutuskan untuk ikut berperan dalam mencegah korupsi melalui jalur pendidikan. Cara yang dipilih oleh Kemdikbud adalah dengan memasukkan nilai-nilai pendidikan antikorupsi ke dalam mata pelajaran di sekolah-sekolah. Hal tersebut dilakukan dengan harapan akan menjadi senjata paling ampuh untuk mencegah terjadinya praktik korupsi di masa yang akan datang. (Simanjuntak, 2017).

Ditanamkannya pendidikan antikorupsi sejak dini kepada siswa di sekolah juga bertujuan agar peserta didik memiliki jiwa antikorupsi. Jiwa anti korupsi inilah yang akan menjadi fondasi bagi mereka untuk tidak melakukan perbuatan korupsi jika mereka sudah dewasa kelak. (Unang, 2017) Oleh sebab itulah program dalam rangka mewujudkan SDGs ini patut untuk segara direalisasikan. Pada dasarnya rencana penerapan pendidikan antikorupsi di sekolah sejalan dengan tujuan pendidikan nasional yaitu berkembangnya potensi peserta didik agar menjadi manusia yang beriman dan bertakwa kepada Tuhan Yang Maha Esa, berakhlak mulia, sehat, berilmu, cakap dan kreatif, mandiri, dan menjadi warga negara yang demokratis serta bertanggung jawab. Inti dari pendidikan antikorupsi sebagaimana tujuan dari pendidikan nasional adalah menanamkan karakter kepada generasi muda agar senantiasa berlaku jujur dan beradab. (Nugraha, 2016)

\section{RUANG LINGKUP}

Kajian ini dibatasi pada upaya yang dilakukan di wilayah sekolah dasar di daerah Jakarta Selatan. Sebagaimana dijelaskan sebelumnya bahwa untuk mencegah tindakan korupsi, maka salah satu yang dapat dilakukan adalah dengan memberikan pengertian kepada masyarakat sejak dini. Kegiatan ini dilakukan dalam ruang lingkup sekolah Madrasah Tsanawiyah (MTs) Al Musyarrofah. Madrasah Tsanawiyah (MTs) Al Musyarrofah merupakan sekolah swasta berbasis kerohanian dengan system asrama (boarding). Yayasan yang didirikan oleh KH. Ahmad Nawawi ini mencakup pondok pesantren, SD/MI, SMP/MTs, dan SMK yang saling terintegrasi. Pada tahun 1998 KH. Ahmad Nawawi menjadikan lembaga pendidikannya menjadi lembaga formal dengan nama Yayasan Al Musyarrofah Jakarta dibawah naungan Departemen Agama RI dan Departemen Pendidikan Nasional. Pendidikan formal yang pertama berjalan ketika itu adalah tingkat Madrasah Tsanawiyah (MTs). Oleh karena permintaan yang begitu besar dari para orang tua santri dan masyarakat agar Yayasan Al Musyarrofah mendirikan sekolah lanjutan 
bagi anak-anak mereka. Setelah 4 tahun kemudian didirikanlah SMK Plus Al Musyarrofah sebuah SMK terpadu dengan penerapan pelajaran berbasis Aliyah.

Saat ini Yayasan Al Musyarrofah telah memiliki berbagai jenjang pendidikan, mulai dari Taman Kanakkanak (RA), Sekolah Dasar Islam (SDI), Madrasah Tsanawiyah (MTs), Sekolah Menengah Kejuruan (SMK) Plus. Yayasan Al Musyarrofah juga memiliki peserta didik dan santri yang berasal dari berbagai daerah di tanah air. Nama Yayasan Al Musyarrofah berubah menjadi Yayasan Al Musyarrofah An-Nawawi. Meskipun saat ini masih sangat dikenal dengan sebutan Al Musyarrofah, tapi secara resmi telah berganti dengan Al Musyarrofah An-Nawawiyyah. Perubahan ini mengikut instruksi dari pemerintah, dikarenakan banyaknya nama-nama Pondok Pesantren yang sama. maka untuk menjadi ciri khas, setiap nama ditambah dengan ciri khasnya masing-masing.

Pondok Pesantren Al-Musyarrofah kini menjelma menjadi sebuah lembaga pendidikan yang siap bersaing dengan lembaga-lembaga pendidikan lainnya. Dari ketekunan seorang K.H. Ahmad Nawawi, AlMusyarrofah siap menjawab tantangan zaman di era globalisasi dan teknologi ini.

Sekarang Pondok Pesantren Al-Musyarrofah telah berkembang pesat, hal ini dibuktikan dengan semakin majunya kegiatan-kegiatan yang diprogramkan dan telah terlaksana dengan baik. Tidak hanya itu, pesantren telah mengembangkan dan melengkapi fasilitas yang ada dengan WIFI. Beberapa fasilitas yang ada di pesantren antara lain;

1. Masjid Nurul Burhan

2. Asrama Putra

3. Asrama Putri

4. Aula Pesantren

5. Gedung Madrasah

6. Lap Komputer dan Internet

7. Lapangan Olahraga

8. Kamar Mandi Putra

9. Kamar Mandi Putri

Pesantren juga semakin meningkatkan kajian-kajian kitab untuk meningkatkan mutu para santrinya. Pondok pesantren juga melatih santri-santrinya untuk hidup mandiri dan bermasyarakat dengan adanya organisasi santri. Dalam organisasi ini mereka digembleng untuk menjadi santri yang berkualitas dan siap terjun dalam dunia yang semakin berkembang. Al-Musyarrofah terus dan terus melebarkan sayapnya untuk menjadi jawaban bagi setiap manusia yang haus akan ilmu Agama.

MTs Al Musyarrofah yang terintegrasi dengan pondok pesantren juga memiliki kegiatan yang sama dengan jenjang pendidikan di lembaga tersebut. Hanya yang membedakan adalah pelajaran yang diberikan. Kegiatan santriwan dan santriwati di sana juga tidak hanya dibekali oleh ilmu agama yang kuat, tetapi diimbangi oleh pemberian materi pendidikan duniawi terutama penguasaan IPTEK.
Untuk level MTs sendiri, guna mengorganisir santri yang jumlahnya tidaklah sedikit, Pondok Pesantren melatih mereka untuk berorganisasi yang membidangi kegiatan ekstrakurikuler seperti muhadharah. Untuk membantu kelancaran kegiatan harian pondok, maka dibuatlah organisasi intra santri yang diberi nama dengan OSIPA (Organisasi Santri Intra Pondok Pesantren AlMusyarrofah)

\section{BAHAN DAN METODE}

Kegiatan ini merupakan Pengabdian dengan cara melakukan Penyuluhan pendidikan antikorupsi kepada anak usia dini. Strategi Pendidikan antikorupsi di Sekolah dilakukan dengan cara mengintegrasikan beberapa nilai dan perilaku anti korupsi ke dalam Pengembangan materi, metode, media, dan sumber belajar yang relevan. Pendidikan Anti Korupsi disesuaikan dengan dengan permasalahan kompleks dalam dunia nyata yang mencakup 3 domain yaitu kognitif (pengalihan pengetahuan), afektif (upaya pembentukan karakter), dan psikomotorik (kesadaran moral dalam melakukan perlawanan) terhadap penyimpangan perilaku korupsi. (Irwansyah, 2018).

Media yang dapat digunakan dalam pembelajaran Pendidikan Anti korupsi diantaranya adalah tabel angka korupsi, media audiovisual seperti video-video yang berhubungan dengan korupsi, studi pustaka tentang negara-negara maju yang hidup tanpa korupsi, media Susu Anti Korupsi, dan dengan permainan yel yel tentang anti korupsi. Sumber Belajar: meliputi media cetak, media elektronik, dokumentasi produk hukum, koran, majalah, buku, annnual report, kitab, CD, internet, audio, visual, audio visual rekaman/ tayangan persidangan kasus korupsi, dan UU terkait kasus korupsi. (Lestari, 2018).

Keberhasilan belajar kelompok tergantung pada kemampuan dan aktivitas anggota kelompok baik secara individual maupun kelompok. Metode: active learning dan student centered learning (SCL) merupakan model pembelajaran yang dapat mengaktifkan anak didik. Siswa terlibat secara aktif dan kreatif dalam proses pembelajaran, metode pemberian keteladanan, penelahan berbagai modus operandi korupsi, serta studi kasus atau lapangan dan pemecahan masalah, pelatihan kejujuran dan kedisiplinan. (Ramadhani, 2017).

Model pembelajaran yang berpusat kepada siswa diantaranya: Model Pembelajaran Investigasi Kelompok (Group Investigation), Student Team Achievement Division (STAD), NHT (Numbered Head Together), Metode Pemecahan Masalah (Problem Solving). Metode Pembelajaran Berbasis Masalah (Problem Based Learning), debate, ex change partner, games, role playing, dan sebagainya. Evaluasi: Teknik evaluasi autentik mengukur aspek verbal, kognitif peserta didik, juga mengukur karakter, keterampilan, kewaspadaan dan cara berfikir siswa dalam mengatasi masalah. Evaluasi yang dikembangkan dalam proses belajar pendidikan anti korupsi terdiri dari dua macam, yaitu test dan non test. 
Evaluasi dengan test menggunakan pertanyaan berbentuk essay untuk menguji pengetahuan (kognisi), sikap (afeksi), dan tindakan (psikomotorik) terkait dengan sejumlah masalah korupsi. Non Tes terdiri: kinerja, keterampilan, kumpulan hasil kerja (karya) siswa, portofolio berisi berbagai pengalaman dan pemikiran tentang problem korupsi. (Wijaya, 2020)

Dalam konteks sekolah sebagai lembaga yang melaksanakan transformasi nilai-nilai budaya masyarakat, terdapat tiga pandangan untuk menyoal hubungan antara

sekolah dengan masyarakat, yakni perenialisme, esensialisme, dan progresivisme. Pandangan perenialisme, sekolah bertugas untuk mentransformasikan seluruh nilai-nilai yang ada dalam masyarakat kepada setiap peserta didik, agar peserta didik tidak kehilangan jati diri dan konteks sosialnya. Esensialisme melihat tugas sekolah adalah menyeleksi nilai-nilai sosial yang pantas dan berguna untuk ditransformasikan seluruh nilai-nilai yang ada dalam masyarakat kepada peserta didik sebagai persiapan bagi perannya di masa depan. Peran sekolah yang lebih maju ada pada progresivisme yang menempatkan sekolah sebagai agen perubahan (agent of change) yang tugasnya adalah mengenalkan nilai-nilai baru kepada peserta didik yang akan mengantarkan peran mereka di masa depan. (Izza, 2019).

\section{PEMBAHASAN}

Kegiatan Pengabdian Kepada Masyarakat (PKM) ini disusun sebagai sumbangan nyata kampus untuk mengenalkan lebih luas tujuan-tujuan yang hendak dicapai dalam Sustainable Development Goals (SDGs). Permasalahan yang ada dalam tujuan 16 dapat dikurangi melalui pendidikan. Kegiatan ini akan terus dilakukan sehingga diharapkan dapat meningkatkan kesadaran masyarakat pentingnya Tujuan 16 sasaran 5 yang berkaitan dengan isu korupsi dan suap. Pihak sekolah sebagai mitra juga memiliki komitmen untuk melanjutkan pendidikan yang mengandung nilai korupsi dapat dilihat pada Gambar 1.

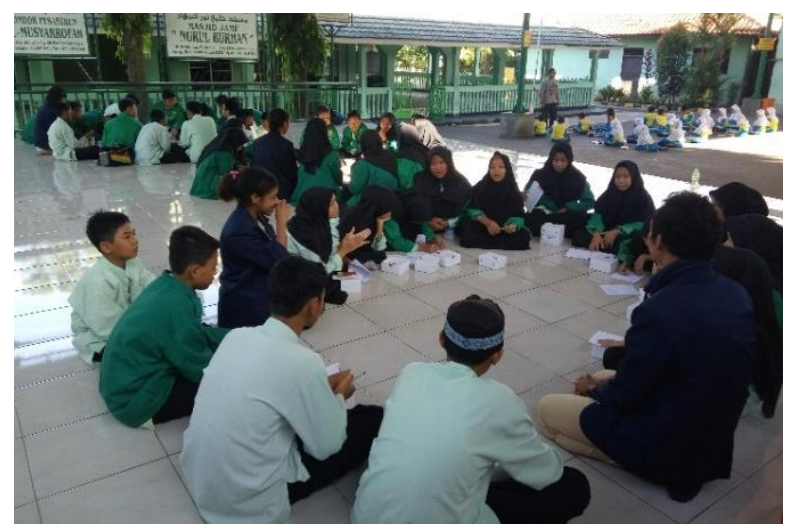

Gambar 1. Sesi pembagian kelompok antar siswa dan mahasiswa
Kegiatan PKM mengenai pendidikan anti korupsi sejak dini dilakukan dengan menggunakan bentuk mini seminar dan diskusi kelompok. Ketua tim menjadi pemakalah untuk menjelaskan mengenai fenomena umum isu korupsi di dunia. Setelah itu, kegiatan dilanjutkan dengan diskusi kelompok yang dimoderatori oleh mahasiswa. Penyelenggara berusaha untuk menumbuhkan disiplin dengan contoh, bukan paksaan, karena kita ingin datang dari dirinya sendiri. Penyelenggara memaparkan mengenai bahaya korupsi dan contoh-contoh kecil di keseharian siswa yang dapat dikategorikan sebagai bentuk korupsi.

Kebiasaan tepat waktu, membuang sampah pada tempatnya, mengikuti peraturan di rumah atau di sekolah adalah beberapa bentuk disiplin yang bisa ditanamkan sejak kecil. Kunci untuk kesuksesannya adalah contoh dan konsistensi. Dengan terbiasa disiplin, siswa tidak akan terbiasa berlaku curang yang nantinya akan menjadi awal dari tindak korupsi. (Amedi, 2018) dapat dilihat pada Gambar 2.

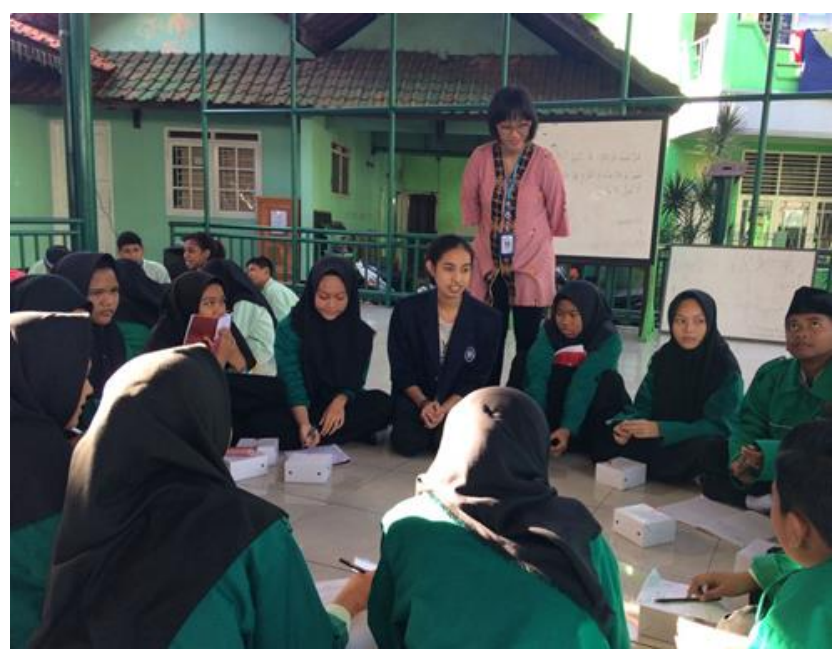

Gambar 2. Diskusi siswa, mahasiswa, dan dosen penyelenggara mengenai tindakan korupsi

Dapat dilihat pada gambar 2, kegiatan diskusi kelompok diikuti oleh 43 siswa pengurus OSIS MTs Al Musyarrofah. Peserta dibagi ke dalam 3 kelompok yang dipandang oleh masing-masing mentor. Mahasiswa sebagai mentor, mengarahkan kelompok untuk mendiskusikan pertanyaan berikut ini:

1. Mengapa korupsi bisa terjadi?

2. Apa saja contoh tindakan korupsi?

3. Bagaimana dampak korupsi terhadap kehidupan berbangsa dan bernegara?

4. Menurut kelompok, pakah tindakan mencontek termasuk kedalam tindakan korupsi?

5. Apakah pernah melihat tindakan korupsi di sekitar? Kemudiaan apa yang dilakukan?

Para peserta terlihat sangat antusias menyampaikan pendapatnya dalam diskusi kelompok tersebut. Perwakilan dari setiap kelompok kemudian menyampaikan apa hasil diskusi mereka dalam sesi 
panel. Siswa menyatakan bahwa menurut mereka mencontek dan berbuat curang dalam ujian dan test harian adalah sebuah tindakan tidak terpuji yang juga termasuk dengan tindakan korupsi. Selain itu, siswa yang membolos menurut mereka juga merupakan asal mula adanya tindak korupsi dalam bentuk waktu belajar.

Dapat dilihat pada Gambar 3, di akhir sesi diskusi panel, moderator membuat kesimpulan diskusi mereka. Setelah ketiga pertanyaan di atas didiskusikan, moderator mengajukan pertanyaan terakhir yaitu apa solusi yang bisa diberikan oleh peserta untuk meminimalisir korupsi?. Penyelenggara mengajarkan konsep adil sesuai usianya, dan mengajari siswa untuk saling berbagi. Penyelenggara juga menanamkan nilai bahwa setiap orang punya hak dan kewajiban yang sama dan harus diperlakukan dengan setara. Siswa diajarkan untuk saling menghormati sesama dan tidak mengambil hak yang menjadi kepunyaan orang lain.

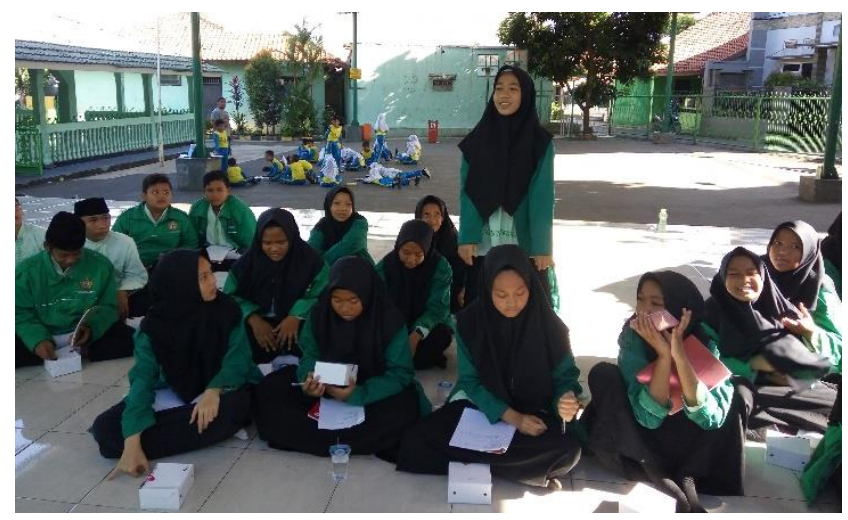

Gambar 3. Antusiasme siswa dalam menyampaikan pendapat

Peserta sangat antusias menyampaikan pendapatnya. Setelah mengikuti seminar dan diskusi kelompok, peserta yang semuanya adalah pengurus OSIS, menyampaikan bahwa sikap jujur, penguatan Komite Pemberantasan Korupsi (KPK) serta ketegasan penegakan hukum dapat mencegah dan meminimalisir tindak suap dan korupsi. Acara ditutup dengan tekad peserta untuk turut mencegah korupsi di Indonesia dan kelak menjadi pejuang anti korupsi.

\section{KESIMPULAN}

Pengalaman Indonesia dalam melawan korupsi bisa menjadi pelajaran yang baik bagi negara-negara lain dalam implementasi SDGs, khususnya poin 16. Indonesia dengan tingkat korupsi yang besar harus bahu membahu dengan dukungan banyak elemen untuk memerangi korupsi. Dengan masih meningkatnya tingkat korupsi, tidak hanya SDGs Poin 16, namun juga berpengaruh terhadap pencapaian poin-poin lainnya. Salah satu upayanya adalah dengan terjun langsung berdiskusi dengan siswa sekolah dasar dan menengah untuk menanamkan fondasi anti korupsi sejak dini. Kegiatan PKM ini adalah untuk membantu pemerintah mewujudkan generasi bebas korupsi. Kegiatan PKM ini mendapat antusiasme yang tinggi dari siswa sekolah dasar dan menengah. Siswa sebagai elemen pemuda yang merupakan agent of change nantinya akan menyebarkan prinsip anti korupsi di lingkungannya masin-masing.

\section{SARAN}

Kegiatan Pengabdian Kepada Masyarakat (PKM) ini disusun sebagai sumbangan nyata kampus untuk mengenalkan lebih luas tujuan-tujuan yang hendak dicapai dalam Sustainable Development Goals (SDGs). Permasalahan yang ada dalam tujuan 16 dapat dikurangi melalui pendidikan. Kegiatan ini disarankan untuk terus dilakukan sehingga diharapkan dapat meningkatkan kesadaran masyarakat pentingnya Tujuan 16 sasaran 5 yang berkaitan dengan isu korupsi dan suap. Pihak sekolah sebagai mitra juga dengan demikian akan memiliki komitmen untuk terus melanjutkan pendidikan yang mengandung nilai korupsi. Pihak sekolah juga diharapkan menanamkan nilai-nilai anti korupsi di setiap mata pelajaran sosial yang ada di kuriulumnya.

\section{DAFTAR PUSTAKA}

Abubakar, A., Prasojo, E., \& Jannah, L. M. (2017). Collaborative Governance in Eradicating Corruption in Indonesia: Challenges and Opportunities. In 1st International Conference on Administrative Science, Policy and Governance Studies (ICAS-PGS 2017) (pp. 160-166). Atlantis Press.

Amedi, A. M. (2018). Analisis Politik Hukum Pendidikan Dasar di Indonesia Demi Menyongsong Era Tujuan Pembangunan Berkelanjutan (Sustainable Development Goals/SDGs). Padjadjaran Law Review, 6.

Badan pusat statistik, (2014), Kajian Indikator Sustainable Development Goals (SDGs). Jakarta: Badan Pusat Statistik.

Bappenas (2015). Rencana Pembangunan Nasional Jangka Menengah 2015-2019. Jakarta: Bappenas

Biermann, F., Kanie, N., \& Kim, R. E. (2017). Global governance by goal-setting: the novel approach of the UN Sustainable Development Goals. Current Opinion in Environmental Sustainability, 26, 26-31.

Fukuda-Parr, S. (2016). From the Millennium Development Goals to the Sustainable Development Goals: shifts in purpose, concept, and politics of global goal setting for development. Gender \& Development, 24(1), 43-52.

Hope, K. R. (2020). Corruption Reduction as a Target of the Sustainable Development Goals: Applying Indicators and Policy Frameworks. In The Emerald Handbook of Crime, Justice and Sustainable Development. Emerald Publishing Limited. 
Irwansyah, I. (2018). How Indonesia media deal with Sustainable Development Goals. In E3S Web of Conferences (Vol. 74, p. 08014). EDP Sciences.

Izza, L. (2019). Menumbuhkan Nilai-Nilai Anti Korupsi pada Anak untuk Membentuk Karakter Melalui "Semai Games" Di MDTA Rabithatul Ulum Pekanbaru. Psychopolytan: Jurnal Psikologi, 2(2), 8495.

Lestari, D. P. (2018). Peningkatan Perilaku Anti Korupsi Melalui Metode Story Telling. Al-Athfal: Jurnal Pendidikan Anak, 4(1), 17-30.

Nugraha, S. A. (2016). Konsep Dasar Pendidikan Karakter. Al-Munawwarah: Jurnal Pendidikan Islam, 8(2), 158-176.

Profil PONDOK PESANTREN AL-MUSYARROFAH. (2020). https://www.almusyarrofah.sch.id/\#

Ramadhani, H. S. (2017). Efektivitas Metode Pembelajaran Scl (Student Centered Learning) Dan Tcl (Teacher Centered Learning) Pada Motivasi Instrinsik \& Ekstrinsik Mahasiswa Psikologi Untag Surabaya Angkatan Tahun 2014 "2015. Persona: Jurnal Psikologi Indonesia, 6(2), 66-74.

Rulandari, N. (2021). Study of Sustainable Development Goals (SDGS) Quality Education in Indonesia in the First Three Years. Budapest International Research and Critics Institute (BIRCI-Journal): Humanities and Social Sciences, 4(2), 2702-2708.

Simanjuntak, Familia Novita. (2017). "Pendidikan untuk Pembangunan Berkelanjutan." Jurnal Dinamika Pendidikan 10, no. 2 169-195.

Thamrin, H. (2020). Educational Aspects in Efforts to Realize SDGs in Indonesia. Saudi Jurnal.

Unang, M.U. (2017). Anak, Perempuan dan Sustainable Development Goals (SDGs). Jurnal Unila.

UNDP Indonesia, November (2015). Konvergensi Agenda Pembangunan Nawa Cita, RPJM, dan SDGs, Jakarta: UNDP Indonesia.

United Nations Development Programme. (2017). Human Development Reports. http://www.hdr.undp.org/en

Wijaya, M. M. (2020). Sosialisasi Penanaman Mindset Pendidikan Anti Korupsi Pada Anak Usia Dini Berdasarkan Peraturan Walikota Bogor No. 28 Tahun 2019 Tentang Penyelengaraan Pendidikan Anti Korupsi. Pakuan Law Review, 6(2), 123-146. 